\title{
Using radon risk to motivate smoking reduction: evaluation of written materials and brief telephone counselling
}

Edward Lichtenstein, Judy A Andrews, Michael E Lee, Russell E Glasgow, Sarah E Hampson

\begin{abstract}
Objective-Radon and cigarette smoking have synergistic effects on lung cancer, even when radon concentrations are relatively low. Working through an electric utility company, we sought to reach smoking households with low radon concentrations and motivate smoking cessation or prohibiting smoking in the home.

Design-Eligible homes $(n=714)$ were randomised to receive: (1) the Environmental Protection Agency's (EPA's) “A citizen's guide to radon"; (2) a specially developed pamphlet; or (3) that pamphlet plus brief telephone counselling.

Procedure-Utility company "bill stuffers" offered free radon test kits to smoking households. All households received radon test results with an explanatory cover letter. Both the specially developed pamphlet and the telephone counselling emphasised that smoking cessation or prohibiting smoking in the home were the optimal risk reduction strategies. Households were followed up at 3 and 12 months after receiving materials.
\end{abstract}

Results-The specially developed pamphlet and the EPA guide yielded similar outcomes. There was a non-significant trend for telephone counselling to produce greater sustained quitting than the specially developed pamphlet, and phone counselling led to significantly more new household smoking bans.

Conclusions-Working through a public utility company is an efficient way to reach smoking households, and brief telephone counselling is a promising method for promoting household smoking bans and cessation in homes alerted to the risk posed by the combination of radon and smoking.

(Tobacco Control 2000;9:320-326)

Keywords: radon risk; smoking cessation; smoking bans; telephone counselling

During the past decade research has identified radon as the second leading cause of lung cancer after smoking. ${ }^{1}$ While high concentrations of radon are present in only $6-7 \%$ of homes in the USA, the far more numerous low readings have synergistic or multiplicative effects for cigarette smokers, thereby greatly increasing the numbers of citizens or households at risk. ${ }^{12}$
As formal smoking prohibitions increase in public places and the workplace, the home remains an entrenched smoking area. About $19 \%$ of all households have at least one smoker and $43 \%$ of children in the USA live in a home with at least one smoker. ${ }^{3}$

The synergy of radon and smoking increases the risk for smokers - and probably nonsmokers - in these households. The identification of novel opportunities for presenting risk information in ways that will motivate smokers is now a priority. The synergistic risk of radon and smoking is one such motivating opportunity or "teachable moment". For homes with smokers, smoking reduction yields much greater risk reduction benefits than does structural mitigation to reduce radon concentrations. ${ }^{4}$ This is especially so for low $(<4 \mathrm{pCi} / \mathrm{l})$ radon concentrations since it is difficult and expensive to reduce radon concentrations further. Even with a radon concentration of $2 \mathrm{pCi} / 1$, there is a 15 -fold difference in risk between smokers and non-smokers. ${ }^{1}$

We devised a novel way to approach households about radon and smoking through a partnership with a local electric utility company. Electric bills can contain inserts (bill stuffers) without increasing the postage, thus providing an inexpensive way to communicate with virtually every household in a given area. Using utility bills for recruitment is especially appropriate since utility companies often test for radon when "sealing" homes for energy efficiency. Tightly sealed, energy efficient homes have the potential for increasing indoor concentrations of radon.

The objective of the study was to test a population based intervention, intended primarily to change smoking behaviour in households where a smoker is present and there are low but detectable concentrations of radon. Two experimental intervention strategies were compared with standard Environmental Protection Agency (EPA) materials on the dependent variables of quitting smoking and banning or restricting smoking in the home. The rationale for our approach and several 3 month follow up outcomes have been reported previously. ${ }^{5}$ This paper focuses on sustained, longer term outcomes and also presents data on predictors of response to the intervention. 


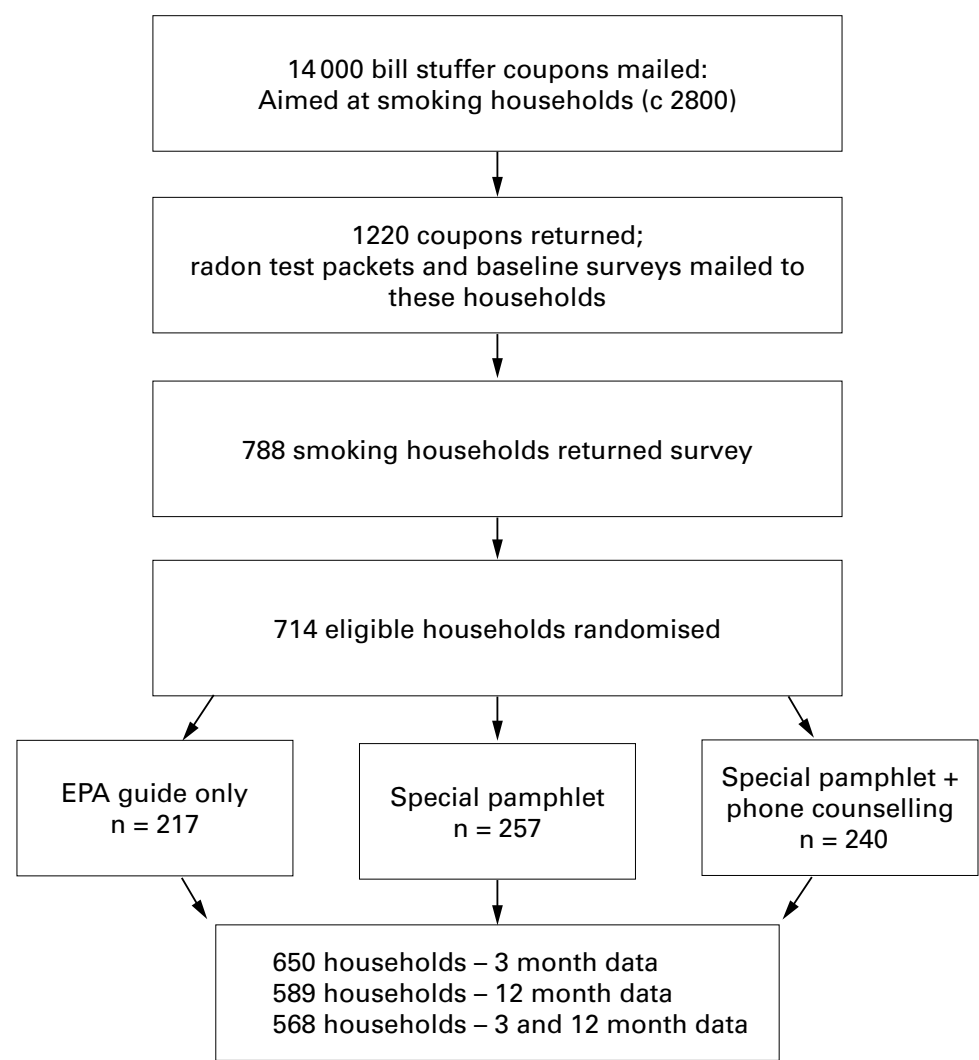

Figure 1 Household recruitment, randomisation, and retention.

\section{Methods}

DESIGN

Eligible households were randomised to one of three intervention conditions: (1) the EPA's "A citizen's guide to radon"; (2) a pamphlet we developed on the basis of formative research, dubbed the ORI pamphlet; or (3) the ORI pamphlet plus telephone counselling. All households received test results of their radon concentrations with a cover letter explaining the results and their implications for action.

\section{RECRUITMENT AND PARTICIPATION}

A flow diagram for recruitment, participation, and assignment is presented in fig 1 . Informational coupons enclosed with customers' utility bills invited households with at least one smoker to request a free radon test kit by completing and returning the coupon along with their utility payment. Recruitment coupons were included in all of the utility bills sent to 14000 customers during October 1996, and the procedure was repeated in December and

Table 1 Demographic and baseline smoking history variables by condition

\begin{tabular}{llll}
\hline & \multicolumn{2}{l}{ Intervention condition } \\
\cline { 2 - 4 } Variable & EPA guide & $\begin{array}{l}\text { ORI } \\
\text { pamphlet }\end{array}$ & $\begin{array}{l}\text { ORI pamphlet + } \\
\text { phone counselling }\end{array}$ \\
\hline Households & $\mathrm{n}=217$ & $\mathrm{n}=257$ & $\mathrm{n}=240$ \\
Respondent's education (\% > high school) & 58.1 & 65.3 & 61.3 \\
\% single family owned home & 78.2 & 85.1 & 79.4 \\
\% previously tested for radon & 1.9 & 3.5 & 2.1 \\
\% with more than one smoker in home & 34.1 & 32.3 & 38.8 \\
\% banning smoking in home & 28.6 & 25.7 & 25.0 \\
Individual smokers & $\mathrm{n}=291$ & $\mathrm{n}=345$ & $\mathrm{n}=354$ \\
Average cigarettes smoked/day & $19.4(11.4)$ & $20.2(11.4)$ & $20.0(10.5)$ \\
Intent to quit smoking (0-10 scale) & $5.4(2.9)$ & $5.5(3.0)$ & $5.4(3.1)$ \\
\hline
\end{tabular}

February 1997. After 30 weeks of recruitment, 1220 coupons requesting a free radon test kit were received, representing over $40 \%$ of the estimated smoking households (we assume that $20 \%$ of households contained a smoker based on a $25 \%$ smoking prevalence at the time of our study and our finding that $54 \%$ of our households contained more than one smoker).

Households returning the coupon were sent a radon test kit along with a baseline survey assessing the demographic characteristics and smoking habits of household members. A $\$ 2$ bill was included as an incentive for returning the survey. From the 1220 radon packets sent, 788 smoking households returned the household survey (106 non-smoking households also requested kits and were sent them). Of these smoking households, 714 were randomised into the study (22 were excluded because of high radon concentrations (see below), 22 had cigar or pipe smokers only, and 30 for miscellaneous reasons). These 714 households contained 1005 smokers, 547 nonsmoking adults, and 469 children under the age of 18. Reflecting the limited ethnic diversity in the area, respondents, for the most part, were white (95\%), with $2 \%$ American Indian, and less than $1 \%$ Latino.

Table 1 summarises key demographic and smoking characteristics for the three intervention conditions. The three conditions were similar on demographic and baseline smoking characteristics. Of the respondents, $65 \%$ were smokers and $35 \%$ were non-smokers in a smoking household. The eligible households had an average of 1.4 smokers per household who smoked an average of 20 cigarettes per day, of which about 10 were smoked inside the home. The mean (SD) contemplation ladder score $^{6}$ for smokers was 5.4 (3.0), indicating much variation in readiness to quit. At baseline, $62 \%$ of households had rules about indoor smoking and $26 \%$ had a rule completely banning smoking inside the house.

The 22 households that tested at or above $4 \mathrm{pCi} / 1$ - the concentration at which the EPA recommends structural mitigation-were excluded from the study because we did not want to complicate intervention materials with material on structural mitigation. These households received their test scores, the EPA guide, advice to quit or reduce smoking, a second test kit to confirm the high reading, and information and referral for structural mitigation.

Households receiving only the EPA guide served as the control group. This 16 page guide contains a wealth of information on radon and mitigation (modifying homes to reduce radon concentrations) including one page on the combined risk of smoking and radon. This page contained a large table comparing the risks for smokers and non-smokers at various concentrations of radon. The guide is available at no cost from the EPA and is routinely sent to households who have tested for radon along with the test results. 
INTERVENTION

We sought to develop an intervention that was both effective and disseminable. The intervention approach was modelled upon low intensity interventions we have used successfully in a variety of health care settings. ${ }^{7}$ We assumed that the radon issue would arouse motivation to engage in risk reducing actions, and the special pamphlet and the telephone counselling directed those actions toward smoking reduction.

On the basis of formative research that included questionnaires, interviews, and focus groups, ${ }^{58}$ we developed a short pamphlet (a folded, double sided, legal size page) that highlighted the point that even at low concentrations of radon, smoking households were at much greater risk than non-smoking households. The pamphlet advised households that quitting smoking or not smoking indoors were the most effective risk reduction strategies, and listed basic tips and strategies for quitting - for example, setting a quit date, using substitute behaviours. Households in the ORI pamphlet condition received this specifically developed piece.

Households in the telephone condition could receive up to two calls. The first call was delivered shortly after the household received their test results, explanatory letter, and ORI pamphlet. The call was brief, but supportive and non-confrontational. The counsellor first clarified any questions about the test results or written materials and then inquired about the respondent's interest in quitting smoking (we tried to talk to the smoker in the household but did not always succeed). Depending on interest or "readiness" to quit," smokers were encouraged to quit or to avoid smoking inside the home. In effect, radon testing and concern about the radon smoking risk served as a "cueto-action" in a manner consistent with the Health Belief Model. ${ }^{10}$ As appropriate, tips or strategies for quitting were offered. At the end of the call, a second call was negotiated if the smoker or household was willing. This call provided additional support and encouragement, and was also sensitive to the participant's progress in taking action to reduce risk.

All households received their radon test results along with a cover letter explaining the results and noting the implications for action. These cover letters emphasised that while the household radon concentration per se was low and not a basis for concern, in combination with smoking, there was a significant risk that could best be addressed by addressing smoking.

ASSESSMENT

Households were assessed at 3 and 12 months after intervention via a mailed questionnaire with a cover letter and a $\$ 2$ bill as a "thank you" for returning the completed questionnaire. After two weeks, a second questionnaire was mailed and, if the household failed to respond within another two weeks, we attempted to complete the assessment by telephone.
The primary outcomes were: (a) smoking cessation; and (b) eliminating or restricting smoking inside the home. The survey respondent was asked to list all members of the household and their current smoking status. Thus, some of the information on smoking outcomes comes from proxies, a procedure sometimes used in prevalence surveys. ${ }^{11}$ Each smoker's interest in quitting was assessed by means of the "contemplation ladder", ${ }^{6}$ an 11 point Likert scale. Smoking restrictions in the home were assessed with a single item asking the respondent to circle the statement that best described "the current smoking rules in your home" (no smoking in house; no smoking when certain people-for example, childrenpresent; restricted to certain areas; no rules). Changes in radon mitigation behaviour-for example, retesting, trying to fix the home-were assessed as secondary outcomes at the 3 month follow up only. The 3 month survey also included items asking about the helpfulness of the written materials and phone calls. Both the 3 and 12 month surveys contained risk perception items which are reported on elsewhere. ${ }^{12}$

\section{Results}

\section{ATTRITION}

Three month follow up data were obtained from $650(91 \%)$ of the 714 eligible households, 12 month data from 589 (82.5\%), and 568 (79.6\%) households completed both surveys. The respondents for a household could vary over time; $75 \%$ of households who provided both 3 and 12 month follow up data had the same respondent on all occasions and there were no differences across conditions. We compared responders and non-responders at both follow up intervals. Among respondents who smoked at baseline, those who returned the 3 month questionnaire smoked significantly fewer cigarettes (mean $20.0 v 26.5$, $\mathrm{t}(459)=3.66, \mathrm{p}<0.001)$ and smoked fewer cigarettes indoors (mean $10.4 v$ 15.5, $\mathrm{t}(456)=3.58, \mathrm{p}<0.001)$ than did nonrespondents. Those who completed the 12 month questionnaire were more likely to be male $\left(49.1 \%\right.$ v $38.4 \% ; \chi^{2}(1, \mathrm{n}=713)=4.78$, $\mathrm{p}<0.05)$ and more likely to be non-smokers $\left(36.3 \%\right.$ v $28.0 \% ; \chi^{2} \quad(1, \mathrm{n}=714)=7.66$, $\mathrm{p}<0.05)$ than non-respondents. Smokers in households with respondents who returned the questionnaire had more interest in quitting smoking (mean $5.6 v 5.0, \mathrm{t}(983)=3.98$, $\mathrm{p}<0.01)$ than did smokers in non-responding households. Further analyses indicated that the relation between attrition and these baseline variables did not vary by intervention condition.

IMPLEMENTATION OF INTERVENTION

The 3 month follow up survey provided information on receipt of intervention components and their perceived helpfulness. Table 2 summarises these findings. Nearly all subjects reported receiving written materials and most read substantial parts of them and reported them to be understandable and helpful. There were no significant differences between the 
Table 2 Self reported receipt/helpfulness of intervention components by condition (3 month survey)

\begin{tabular}{|c|c|c|c|}
\hline \multirow[b]{2}{*}{ Variable } & \multicolumn{3}{|c|}{ Intervention condition } \\
\hline & $\begin{array}{l}\text { EPA guide } \\
(n=202)\end{array}$ & $\begin{array}{l}\text { ORI } \\
\text { pamphlet } \\
(n=229)\end{array}$ & $\begin{array}{l}\text { ORI pamphlet }+ \\
\text { phone counselling } \\
(n=219)\end{array}$ \\
\hline$\%$ received written information & 96.3 & 89.1 & 92.5 \\
\hline Amount of material read $(1-5 ; 5=$ all $)$ & $4.4(0.88)$ & $4.5(0.80)$ & $4.3(1.14)$ \\
\hline$\%$ other smokers in home read material & 64.5 & 60.7 & 59.5 \\
\hline Mean helpfulness of materials $(1-5 ; 1=$ very helpful $)$ & $1.9(1.1)$ & $2.1(1.1)$ & $1.8(1.1)$ \\
\hline Materials hard/easy to understand $(1-5 ; 5=$ easy) & $4.3(0.91)$ & $4.3(0.99)$ & $4.4(0.90)$ \\
\hline Mean helpfulness of phone calls $(1-5 ; 1=$ very helpful $)$ & $\mathrm{N} / \mathrm{A}$ & N/A & $2.3(1.4)$ \\
\hline Mean supportiveness of call $((1-5 ; 1=$ very supportive $)$ & N/A & $\mathrm{N} / \mathrm{A}$ & $1.6(1.1)$ \\
\hline
\end{tabular}

No significant differences among conditions; N/A, not applicable.

Table 3 Reported quit rates (\%/n) at 3, 12, and both 3 and 12 month follow up by condition for all smokers identified at baseline

\begin{tabular}{|c|c|c|c|}
\hline \multirow[b]{2}{*}{ Variable } & \multicolumn{3}{|c|}{ Intervention condition } \\
\hline & $\begin{array}{l}\text { EPA guide } \\
(n=302)\end{array}$ & $\begin{array}{l}\text { ORI } \\
\text { pamphlet } \\
(n=349)\end{array}$ & $\begin{array}{l}\text { ORI pamphlet }+ \\
\text { phone counselling } \\
(n=355)\end{array}$ \\
\hline 3 month follow up & $6.3 \%(19)$ & $7.4 \%(26)$ & $11.0 \%(39)$ \\
\hline 12 month follow up & $11.0 \%(33)$ & $8.6 \%(30)$ & $12.1 \%(43)$ \\
\hline Both 3 and 12 month follow up & $4.3 \%(13)$ & $4.3 \%(15)$ & $7.0 \%(25)$ \\
\hline
\end{tabular}

EPA guide and the ORI pamphlet. The telephone calls were rated as fairly supportive, but only somewhat helpful.

Of the 240 households assigned to the telephone counselling condition, 195 (82\%) received at least one call and $95(40 \%)$ received more than one call. The mean (SD) time of the first call was 10.4 (5.4) minutes; for the second call it was 5.8 (4.9) minutes. These times reflect our intent that the calls be motivational and supportive with only modest levels of interactive counselling.

OUTCOME ANALYSES

For smoking, the primary outcome was quit at both the 3 and 12 month follow up, a measure of sustained abstinence. For smoking bans, 3 and 12 month results are considered separately. The outcome analyses emphasise an "intent-to-treat" model where subjects or households lost to follow up are considered smokers (or to not have a ban). Outcomes for these variables are also reported for those subjects who provided follow up data. Secondary outcomes were assessed only for those providing follow up data.

For some outcome analyses-for example, household smoking bans-households were both the unit of assignment and the unit of analysis. For outcomes related to smoking - for example, smoking cessation-individuals were the unit of analysis, and about one third of households contained more than one smoker. An examination of intrahousehold dependence for smoking status at each follow up for these multiple smoker homes found the intraclass

Table 4 Percentage ( $n$ ) of households that allowed smoking at baseline with smoking bans at follow up

\begin{tabular}{|c|c|c|c|}
\hline \multirow[b]{2}{*}{ Variable } & \multicolumn{3}{|c|}{ Intervention condition } \\
\hline & $\begin{array}{l}\text { EPA guide } \\
(n=155)\end{array}$ & $\begin{array}{l}\text { ORI pamphlet } \\
(n=192)\end{array}$ & $\begin{array}{l}\text { ORI pamphlet }+ \text { phone } \\
\text { counselling }(n=180)\end{array}$ \\
\hline 3 month follow up & $11.0 \%(17)$ & $6.8 \%(13)$ & $12.8 \%(23)$ \\
\hline 12 month follow up & $14.2 \%(22)$ & $9.9 \%(19)$ & $17.2 \%(31)$ \\
\hline
\end{tabular}

correlations for 3 month, 12 month, and sustained abstinence were $0.005,0.007$, and 0.010 , respectively. The size of the intraclass correlations - which pertain to only $54 \%$ of the sample of smokers-suggests that the intrahousehold dependence of smoking outcomes would minimally affect both type I and type II error rates. Hence, the design effect, smokers nested within households, was ignored and smokers were treated as independent for all analyses.

All outcomes were assessed using planned orthogonal comparisons. Based on our formative research, we expected that the ORI pamphlet would be superior to the EPA guide and prior research ${ }^{13}$ suggested that adding telephone counselling would be superior to written materials alone. The contrasts were: (1) EPA guide versus the combination of ORI pamphlet and ORI pamphlet plus telephone counselling; and (2) ORI pamphlet versus ORI pamphlet plus telephone counselling.

Table 3 displays quit rates at 3 month, 12 month, and both 3 and 12 month follow up for all baseline smokers. Planned comparisons revealed no significant differences between the EPA guide and the combined conditions of ORI pamphlet and that pamphlet plus telephone counselling (3 month: $\chi^{2}$ (1, $\mathrm{n}=1005)=2.35, \mathrm{p}<0.10 ; 12$ month: $\chi^{2}(1$, $\mathrm{n}=1005)=0.08$, NS; both 3 and 12 months: $\left.\chi^{2} \quad(1, \mathrm{n}=1005)=0.78, \quad \mathrm{NS}\right)$. Planned comparisons between the ORI pamphlet and that pamphlet plus telephone counselling at all end points were in the predicted direction, but not significant (3 month: $\chi^{2}(1, \mathrm{n}$ $=704)=2.63, \mathrm{p}<0.10 ; 12$ month: $\chi^{2}$ (1, $\mathrm{n}=704)=2.34, \mathrm{p}<0.10) ; 3$ and 12 months: $\chi^{2}(1, \mathrm{n}=704)=2.47, \mathrm{p}<0.10$; all one tailed tests). Inspection of the quit rates suggests that the telephone counselling tended to be better than either the EPA guide or the ORI pamphlet and that the two written materials conditions performed similarly. With an analysis, limited to participants for whom both baseline and follow up data were available, the telephone counselling was significantly better than the ORI pamphlet alone at both 12 months $\left(12.1 \%\right.$ v $18.8 \% ; \chi^{2} \quad(1, \mathrm{n}=477)=4.10$, $\mathrm{p}<0.05)$ and at both 3 and 12 months $(6.3 \%$ $\left.v 11.3 \% ; \chi^{2}(1, \mathrm{n}=460)=3.56, \mathrm{p}<0.05\right)$.

In households assigned to the telephone counselling condition, telephone counselling effects were examined more closely by comparing quit rates for those receiving zero, one, or two calls. A suggestive though not significant dose response relation was found. Sustained (both 3 and 12 month) quit rates were $5.6 \%, 6.6 \%$, and $8.2 \%$ for zero, one, and two phone calls, respectively $\left(\chi^{2} \quad(2\right.$, $\mathrm{n}=355)=0.54)$.

HOUSEHOLD SMOKING BANS

Table 4 presents follow up data on smoking bans for households reporting no ban at baseline, again using an intent-to-treat analysis. The planned comparisons between the EPA guide and the combined ORI pamphlet and that pamphlet plus phone counselling were not significant ( 3 months: $\chi^{2}(1, \mathrm{n}=526)=0.90$, 
NS; 12 months: $\chi^{2}(1, \mathrm{n}=526)=0.05$, NS). The second planned comparison showed that telephone counselling plus the ORI pamphlet was superior to the ORI pamphlet alone for both end points (3 months: $\chi^{2}$ (1, $\mathrm{n}=371)=3.77, \mathrm{p}<0.05 ; 12$ months: $\chi^{2}(1$, $\mathrm{n}=371)=4.21, \mathrm{p}<09.05)$. The EPA guide produced smoking bans intermediate between the other two conditions. A post hoc analysis revealed no difference between the EPA guide and the ORI pamphlet plus telephone counselling. The pattern of results for only those households providing follow up data was very similar to the intent-to-treat analyses. Telephone counselling effects again were examined by comparing households which received zero, one or two calls. Households receiving one or two calls tended to have new bans at 12 months $(18.9 \%)$ more than those receiving no calls $(9.4 \%)$, but the difference was not significant $\left(\chi^{2}(1, \mathrm{n}=180)=1.68\right.$, $\mathrm{p}<0.19)$.

The relation between household smoking bans and quitting smoking was examined. At 3 months, $38.8 \%$ of those households with at least one smoker who quit smoking instituted a new household smoking ban, as compared to $7.1 \%$ of those households where no smokers quit $\left(\chi^{2} \quad(1, \mathrm{n}=526)=49.12, \mathrm{p}<0.001\right)$. Similarly, at 12 months, $46.6 \%$ of those households with at least one member who quit smoking instituted a new smoking ban compared to $9.6 \%$ where no members quit smoking $\left(\chi^{2}(1, \mathrm{n}=526)=59.59, \mathrm{p}<0.001\right)$. Quitting and establishing household smoking bans are interrelated.

SECONDARY ANALYSES

Changes in smoking rates for those who did not quit smoking and in behaviours related to radon mitigation were also examined using covariance analyses to adjust for baseline levels on these continuous measures. As previously reported, ${ }^{5}$ at 3 months follow up telephone counselling led to reported reductions in smoking and to other radon mitigation behaviours such as retesting for radon or trying to fix the house to reduce radon compared to written materials only. At 12 month follow up, controlling for extent of smoking at baseline, family members who received the EPA booklet smoked more cigarettes than those in the other two conditions combined (adjusted means $20.72 v 19.29, \quad \mathrm{~F} \quad(1, \mathrm{n}=572)=3.53$, $\mathrm{p}<0.05)$; those in the ORI pamphlet condition smoked more cigarettes than those in the ORI pamphlet plus telephone counselling condition (adjusted means $19.83 v$ $18.64, \mathrm{~F}(1, \mathrm{n}=394)=2.83, \mathrm{p}<0.05)$. There were no differences between groups regarding cigarettes smoked inside the home. (The intraclass correlation for decreased cigarette smoking was 0.013; for decreased cigarettes smoked inside, 0.016.) Radon mitigation behaviours were not assessed at 12 months since we assumed these actions-taken only by relatively few households - would occur within the first 3 months of the intervention.
PREDICTOR ANALYSES

Using data from all smoking household members, we predicted quitting smoking at each end point from the following variables measured at baseline: number of cigarettes smoked, proportion of cigarettes smoked indoors, intention to quit smoking, and the presence of other smokers in the home. We examined the interaction between intervention condition (assessing the effect of each planned contrast separately) and each of these predictors. Across conditions, both number of cigarettes smoked at baseline and intention to quit smoking (contemplation ladder) predicted 3 and 12 month quitting, as well as consecutive quit at both 3 and 12 months (intention to quit: odds ratio (OR) 1.24, 95\% confidence interval (CI) 1.10 to 1.40 ; cigarettes/day: OR 0.96 , reciprocal OR $1.04,95 \%$ CI 1.01 to 1.08). The second planned contrast - the ORI pamphlet plus telephone counselling condition versus the ORI pamphlet alone-also significantly predicted cessation at all end points. With this contrast in the equation, number of cigarettes smoked and intention to quit remained significant predictors. The interaction of this contrast with each predictor variable was not significant. We also predicted new household bans from children present in the home and the number of smokers in the home. Controlling for baseline bans, neither variable was a significant predictor.

\section{Discussion}

Working with a public utility company proved to be a very effective way to reach smoking households and engage them with the radonsmoking synergy issue. Over $40 \%$ of the estimated smoking households in our population returned coupons. The research sample was quite cooperative with $91 \%$ providing 3 month follow up data, $82.5 \%$ providing data at 12 months, and $80 \%$ at both follow up assessments. These response rates are comparable to those attained in health care setting interventions, ${ }^{14}$ and attrition rates were similar across the three conditions. The utility company received only positive feedback from customers, and their staff proposed authoring a short paper on the radon-smoking programme that was published in a trade journal. ${ }^{15}$

Planned orthogonal comparisons on quit rates and smoking bans partially confirmed expectations that telephone counselling would be more effective than the ORI pamphlet only. These differences were significant for bans at both 3 and 12 month follow up, but did not reach significance for the key smoking cessation outcome-quitting at both 3 and 12 month follow up using the intent-to-treat model. The relative effectiveness of telephone counselling in this study is consistent with a meta-analytic review of randomised trials evaluating this intervention modality. ${ }^{13}$ More consistent delivery of the telephone intervention might increase the impact of the intervention. Nearly $20 \%$ of households received no calls and less than half received two calls; and both quitting and new bans tended to increase 
as the number of calls increased. Staffing problems were partly responsible for our not counselling more households.

The second set of planned comparisons revealed no significant differences between the EPA guide and the combination of the ORI pamphlet and that pamphlet plus phone counselling. Contrary to our expectation, the EPA guide was consistently equal to or slightly superior to the ORI pamphlet with respect to both quitting smoking and bans or smoking restrictions. We invested considerable formative research in developing the ORI pamphlet, intending it to be short, focused, and more readable than the EPA guide, which was much more lengthy and said relatively little about the smoking-radon synergy. Process data, however, indicated that ratings of the two pamphlets were similar. Perhaps the "official" status of the EPA guide as a government document outweighed its other drawbacks. In any case, these results replicate findings in the smoking cessation literature showing that different kinds of written materials usually do not produce differences in quit rates. ${ }^{16}$ Although this was not tested directly, a combination of the EPA guide and telephone counselling should be as or more effective than the ORI pamphlet and telephone counselling.

The overall quit rates are modest as would be expected from a low intensity intervention with participants lost to follow up counted as smokers. The sustained quit rates, in fact, are quite similar to those reported by Hollis and colleagues ${ }^{14}$ in a primary care setting using the same sustained quitting measure as we employed. Hollis and colleagues' intervention comprised of clinician advice, a targeted video, written materials and brief counselling from a nurse, and one brief follow up telephone support call. Their intervention yielded a $7 \%$ quit rate compared to $4 \%$ for clinician advice only, a significant difference given their considerably larger sample size.

While $26 \%$ of households containing smokers had household smoking bans at baseline, telephone counselling led to a significant increase in such bans. Many smokers seem sensitive to the effects of environmental tobacco smoke and choose not to smoke in their homes. We note, however, that bans and quitting were strongly interrelated; most, but not all, new bans occurred in households where someone quit smoking.

Quitting smoking was associated with greater readiness to quit and lower rates of smoking consistent with many other reports..$^{9}{ }^{14}$ These factors, however, did not interact with treatment condition; telephone counselling was effective over a range of individual and household characteristics.

Some limitations of this study should be noted. We relied on self reports of smoking cessation, including some proxy reporting. While this might inflate overall quit rates, it is very unlikely to affect differences among conditions. ${ }^{17}{ }^{18}$ Our partnership with one local utility worked very well. How well our approach generalises to other utility companies and to households with higher radon concentrations remains to be examined. Our sample population was almost entirely white. A recent qualitative study suggests that African Americans are more suspicious of government sponsored materials like the EPA guide used in this study. ${ }^{19}$ Although the recruitment coupons were aimed at all smoking households, only about $40 \%$ responded and about $25 \%$ eventually participated. An intervention through utility companies does not have the potential to reach virtually all smokers in the population of interest as do, for example, health care setting programmes. $^{7}$ However, virtually all households can be reached via utility companies, including smokers who do not access health care settings.

Focusing on the radon-smoking synergy and working through utility companies seems very promising. Our emphasis on smoking reduction rather than remediating high radon homes is consistent with the analyses presented by Warner and his colleagues, ${ }^{40}$ and targeting households with smokers is also consistent with the recommendations of Kennedy and associates. $^{21}$ This approach provides a novel way of demonstrating the dangers of smoking and second hand smoke, and utility companies can reach large populations of households. It has also been suggested the radon-smoking synergy "...can now be used in a new publicity campaign against smoking, focused on the previously unappreciated additional dangers of smoking that stem from its synergism with other airborne carcinogens". ${ }^{2}$

Preparation of this paper was supported by grant RO1 CA68186-03 from the National Cancer Institute. We thank the staff and customers of the Emerald People's Utility District for their cooperation; Gallipot Inc for supplying radon test kits; Lyn Foster, Maureen Barckley, Barbara Eisenhardt, and Shari Reyna for help with project management, data analyses and phone counselling; and Connie Key for help with the manuscript.

1 Environmental Proptection Agency. Technical support document for the 1992 citizen's guide to radon (EPA 400-R-92011). Washington, DC: Environmental Protection Agency, 1992 .

2 Reif AE, Heeren T. Consensus on synergism between cigarette smoke and other environmental carcinogens in the
causation of lung cancer. Adv Cancer Res 1999;76:161-86.

3 Pirkle JL, Flegal KM, Bernert JT, Brody DJ, Etzel RA, Maurer KR. Exposure of the US population to environmental tobacco smoke: the third national health and nutrition examination survey, 1988 to 1991. ҒAMA 1996; tion examination $1233-40$.

4 Warner KE, Mendez D, Courant PN. Toward a more realistic appraisal of the lung cancer risk from radon: the effects of residential mobility. Am F Public Health 1996;86:12227.

5 Lee ME, Lichtenstein E, Andrews JA, et al. Radon-smoking synergy: a population-based behavioral risk reduction approach. Prev Med 1999;29:1-6.

6 Biener L, Abrams DB. The contemplation ladder: validation of a measure of readiness to consider smoking cessation. Health Psychol 1991;10:360-5.

7 Lichtenstein E, Hollis JF, Severson HH, et al. Tobacco cessation interventions in health care settings: rationale, model, outcomes. Addict Behav 1996;21:709-20.

8 Hampson SE, Andrews JA, Lee ME, et al. Lay understanding of synergistic risk: the case of radon and cigarette smoking. Risk Anal 1998;18:343-50

9 Prochaska JO, Velicer WD. The transtheoretical model of health behavior change. Am $\mathcal{F}$ Health Promot 1997;12:38-48.

10 Sutton S. Social-psychological approaches to understanding addictive behaviours: attitude-behaviour and decisionmaking models. Br $\mathcal{F}$ Addict 1987;82:355-70.

11 COMMIT Research Group. Community intervention trial for smoking cessation (COMMIT): II. Changes in adult cigarette smoking prevalence. Am f Public Health 1995; 85:193-200.

12 Hampson SE, Andrews JA, Lee ME, Lichtenstein E, Barckley $M$. Radon and cigarette smoking: perceptions of this synergistic health risk, Health Psychol 2000;19:247-52. 
13 Lichtenstein E, Glasgow RE, Lando HA, et al. Telephone counseling for smoking cessation: rationales and metacolytic review of evidence. Health Educ Res 1996;11:24357.

14 Hollis JF, Lichtenstein E, Vogt TM, et al. Nurse-assisted counseling for smokers in primary care. Ann Intern Med 1993;118:521-5.

15 Morrow A, Lee ME. A utility becomes a public health crusader. Public Power 1998;56:44-5.

16 Curry SJ. Self-help interventions for smoking cessation. $\mathcal{F}$ Consult Clin Psychol 1993;61:790-803.

17 Glasgow RE, Mullooly JP, Vogt TM, et al. Biochemical validation of smoking status in public health settings: pros, cons, and data from four low-intensity intervention trials. Addict Behav 1993;18:511-27.
18 Velicer WF, Prochaska JO, Rossi JS, et al. Assessing outcome in smoking cessation studies. Psychol Bull 1992;111: $23-41$.

19 Witte K, Berkowitz JM, Lillie JM, et al. Radon awareness and reduction campaigns for African Americans: a theoretically based evaluation. Health Education \& Behavior 1998;25:284-303.

20 Mendez D, Warner KE, Courant PN. Effects of radon mitigation vs smoking cessation in reducing radon-related risk of lung cancer. Am f Public Health 1998;88:811-2.

21 Kennedy CJ, Probart CK, Dorman SM. The relationship between radon knowledge, concern and behavior, and health values, health locus of control and preventive health behaviors. Health Educ Q 1991;18:319-29.

\section{CALENDAR OF EVENTS}

Full details of events to be included in the calendar should be sent to Rachel Harvey, Editorial Services Manager, BMF Specialist fournals, BMA House, Tavistock Square, London WC1H 9fR, UK; rharvey@bmjgroup.com

5th Brazilian-Luzitan congress on Senology

18-22 October 2000, Brasilia, Brazil Further details: Brazilian Senology Society, CLN 201 BI. A Salas 109/111, 70832 -510 Brasilia-DF, Brazil. (Tel +55 61224 3895; fax +55 61321 4875; bearzi@ bearzieventos.com.br)

8th International Cochrane Colloquium

25-29 October 2000, Cape Town, South Africa

Further details: Ms C Daries/Ms M Salomo, Conference Coordinators, South African Medical Research Council, PO Box 19070, Tygerberg, South Africa 7505. (Tel +27 21938 0433/0202 Fax +27 21 938 0395/0418; charleen.daries@mrc.ac.za; mandy.salomo@mrc.ac.za)
National Lung Cancer Awareness Day 12 November 2000

Further details: Carolyn Clary-Macy, University of California, San Francisco/ Mount Zion Cancer Center, USA. (http:// cc.ucsf.edu/news/lung_ca_awareness.html or ALCASE at www.teleport.com/ alcase)

First Kuwait International Conference on Lung Cancer-Prevention and Treatment

13-15 November 2000, Kuwait

Further details: Kuwait Society of Smoking and Cancer Prevention, Qadisaya, Block 1, Street 14, Bldg 2, PO Box 26733, Safat,

13128 Kuwait, Kuwait. (Tel + 965253 0120; fax + $965251 \quad 0137$; futureks@ncc.moc.kw)

\section{UICC International Smokeout}

16 November 2000

Further details: International Union Against Cancer, Geneva, Switzerland. $\begin{array}{lllll}(\mathrm{Fax} & +41 & 22 & 809 & 1810 \text {; }\end{array}$ education@uicc.org)
Sixth International Congress of Behavioral Medicine

15-18 November 2000, Brisbane, Queensland, Australia

Further details: Intermedia, PO Box 1280, Milton, Queensland, 4064,

Australia. (Tel +61 73369 0477; fax +61 73369 1512; ICBM@im.com.au; www.icbm2000.conf.au)

World Assembly on Tobacco Counters Health-WATCH 2000

4-8 December 2000, New Delhi, India Further details: Dr Vimal Arora, 509-B Arita Vihar, 110044 New Delhi, India. (Tel +91 11694 4551; fax +91 11694 4472; varora@ndf.vsnl.net.in)

92nd American Association for Cancer Research Annual Meeting 24-28 March 2001, New Orleans, USA

Further details: American Association for Cancer Research, Public Ledger Building, Suite 816, 150 South Independence Mall West, Philadelphia PA 19106-3483, USA. (Tel +1 215440 9300; fax +1 215351 9165; meetings@aacr.org) 